\title{
The dynamics of personal potential of students learning at the pedagogical university in the metropolis and the regional center
}

\begin{abstract}
The main aim of this study is to assess the dynamics of students' personal qualities in the process of studying at a university from the first to the fourth year in a megacity at the Novosibirsk State Pedagogical University and its branch in the regional center of Kuibyshev. A study of the personal characteristics of female students of the 1st and the 4th courses $(n=201)$ studying in the natural sciences and humanities was performed. The following methods were used to characterize the personal potential: Personality self-determination, Life satisfaction, Self-Organization activity, the Viability, Quality of life and satisfaction. The results indicate that there are significant differences in the dynamics of indicators of the personal potential of female students of the NSPU for the period of study, depending on the characteristics of the socio-pedagogical environment of universities in the metropolis and regional center. Students studying in metropolis have the higher level almost of all mentioned parameters of personal potential than girls studying at the regional University branch. The specificity of such differences is associated with a change in the psychosocial status of students during the period of study at the university due to the influence of both positive and negative social and environmental, economic and cultural factors.
\end{abstract}

Volume 6 Issue 6 - 2019

\author{
Roman Aizman,' Igor Galay, ${ }^{2}$ Alexey Lebedev' \\ 'Department of Anatomy, Physiology \& Life Safety, Novosibirsk \\ State Pedagogical University, Russia \\ ${ }^{2}$ Department of Physical Culture, Novosibirsk State Pedagogical \\ University, Russia
}

Correspondence: Aizman Roman, Doctor of Biological Sciences, Professor, Honored worker of science of the Russian Federation, Head of the Department of Anatomy, Physiology and Life Safety, Novosibirsk State Pedagogical University, Russia, Tel +79139119564, Email aizman.roma@yandex.ru

Received: October 15, 2019 | Published: November 15, 2019

Keywords: metropolis, pedagogical, personal potential, psychosocial potential, selfrealization

\section{Introduction}

The significance and responsibility of the state's education system is traditionally considered not only as an indicator of socioeconomic level and cultural development of society, but also as a base for the intellectual, social and personal growth of the young generation. Reforming the modern pedagogical system, restructuring its priorities, introducing new educational standards, demand a new higher level of requirements for the quality of high education, the readiness of university graduates for full-fledged life and professional activities in the context of modern social challenges. At the same time, the significant changes in the qualitative composition of students, insufficient funding of the higher pedagogical school and the tendency to view the education system as a service sector inevitably lead to a decline in the teacher's social status, loss of prestige of pedagogical education, and outflow of intellectual youth from the pedagogical industry. ${ }^{1}$ Thus, the problem of timely assessment of the psychosocial potential of university students and the development of an appropriate strategy for its implementation may be a key factor in resolving existing contradictions and an effective tool for improving the quality of education and the socio-psychological adaptation of students in higher education. ${ }^{2,3}$

Despite the fact, that the influence of intellectual potential on academic achievement is reasonably regarded as an important prerequisite for successful professional activity, many authors consider the personal qualities and psychological health to be the determining factors in achieving successful activity in general..$^{4-7}$ Firstly, modern graduates of higher education institutions present not so much with the requirements for a ready-made set of professionally significant personal qualities, as with the ability to adapt and "grow" in the profession. In addition, it is obvious that the ability to analyze their activities, quickly construct professional skills and develop new professional zones is possible only by updating the psychosocial qualities. ${ }^{8}$ That is why the greatest interest, in the context of disclosing the psychosocial development of students, is the study the developmental level and realization of the psycho-physiological and personal potential, as the determining factors of students' readiness not only to master, but also to develop the pedagogical system as an environment for subsequent professional success. In the literature, psychosocial personality traits and methods for assessing the characteristics of psycho-physiological and personal development are described in sufficient details, ${ }^{9,10}$ at the same time, the dependence of these parameters on the specifics of the educational and socio-cultural environment requires further study. This work is devoted to the description of a psychosocial "portrait" of pedagogical university graduates living in a metropolis and a district center.

Professional success is the result of self-realization in the profession, ensuring high social status, financial security, career advancement. Professional success is one of the most important components of human development and socialization ${ }^{11}$ and depends on many determinants: professional knowledge, skills and individual qualities, among which the ability to use one's personal potential is one of the determining factors. ${ }^{12}$ 
Upon receipt of vocational education, students are assessed on exams and tests by the level of demonstrated knowledge and skills, less often by methodological and practical skills, and the personal qualities of a graduate's preparedness for professional work go into the background. At the same time, the long-term practice confirms that the value of a specialist, his professional success depends on his confidence, activity, self-organization, ability to manage his emotions, adaptability to environmental conditions. All these qualities and the possibility of their implementation in professional activities, according to research by Russian and foreign authors, largely depend on the level of human self-esteem. ${ }^{13-20}$ Thus, in the process of studying at a university, students must form not only narrow professional qualities, develop intelligence, but also socially adapt to changing environmental conditions, developing individual psychological resources. As a rule, it is the presence of high personal potential that can ensure, if necessary, the mobilization of intellectual, creative and other types of activity, contributing to the achievement of productivity and productivity of activities. ${ }^{21}$

In our research, we relied on the concept of personal potential of D.A. Leontiev. From his point of view, personality should be considered as an integral higher mental function, and by personal potential it is necessary to understand the systemic organization of personal characteristics that form the "core of personality" and reflect the level of personal maturity. By definition, of D.A. Leontiev, personal potential is an integral characteristic of the individual psychological characteristics of a person, which is the basis of his ability to proceed from stable internal criteria and guidelines in his life and to maintain the stability of activity and semantic orientations against the background of pressures and changing external conditions; the characteristic reflecting "a measure of overcoming by the person of the set circumstances, eventually, overcoming by the person itself", Following DA Leontiev, to the criteria of personal potential, we attribute indicators of resilience, self-organization of activity, selfdetermination of personality and satisfaction with life. In addition, in our opinion, in order to predict the individual characteristics of a person, it is important to take into account the system of basic beliefs that he has developed and his career orientations, which stimulate activity.

In literary sources, the dynamics of indicators of students' personal potential during the period of study at the university and the specificity of their reaction to the influence of social, environmental and psychophysiological factors ${ }^{22,23}$ presents still insufficiently. In addition, the problem of the outflow of promising youth and qualified personnel from the education system remains relevant, this tendency is particularly acute in the province, due to the cultural and economic backwardness of regional centers. ${ }^{24}$ In this regard, it was of great interest to us to assess the dynamics of students' personal qualities in the process of studying at a university from one to four years in a megacity and small city.

\section{Materials and methods}

At the first stage of work at the Novosibirsk State Pedagogical University and its branch in the regional center of Kuibyshev, we conducted a study of the personal characteristics of female students of the 1st and 4th courses $(n=201)$ studying in the natural sciences and humanities. The following methods were used to characterize the personal potential: "Personality self-determination scale (B. Sheldon; in adaptation and modification E.N. Osina, 2007)", "Life satisfaction scale" (E. Diener 1985; in adaptation D.A. Leontiev, E.N. Osina, 2005), "Activity Self-Organization Questionnaire" (E.Yu. Mandrikova, 2007), "Viability Test" (S. Muddy 2002, modified by D.A. Leontiev and E.I. Rasskazova, option E.N. Osina 2006), "Questionnaire of the quality of life and satisfaction" (M. Ritner in the adaptation of EI Rasskazova 2012), as well as the personal questionnaire of the quarries Career Anchors' Orientations (E. Shane in the Adaptation of V.A. Chiker, VE Vinokurova 2012). ${ }^{25}$ For data analysis, descriptive statistics methods were used (Student's t-test). Main calculations were performed using the Statistics 7.0 software package and were considered significant at $\mathrm{p} \leq 0.05$.

\section{The results of the study}

Of great importance for the successful psychosocial adaptation of students, the formation of conditions for personal growth and the implementation of the objectives have the ability of young people to rational organization of life. The results obtained when testing the subjects on a scale of "Self-organization of activity" (Table 1) indicate that in the group of Novosibirsk students on subscales "Planarity", "Self-organization", "Orientation to the present", and "Selforganization index" were observed statistically significant positive differences in the dynamics of indicators from the first to the fourth course, and the level of values varied from low to medium compared with the normative values determined for students of university cities. $^{26}$

Table I Comparison of indicators on a scale of "Self-organizing activity"

\begin{tabular}{llllllll}
\hline Indicator & \multicolumn{3}{c}{ Novosibirsk } & \multicolumn{5}{c}{ Kuibyshev } \\
\cline { 2 - 8 } & I course & 4 course & $\boldsymbol{p}$ & I course & 4course & $\boldsymbol{p}$ \\
\hline Regularity & $17,20 \pm 1,03$ & $19,70 \pm 0,58$ & $*$ & $16,81 \pm 0,71$ & $17,21 \pm 0,78$ & $\mathrm{n} / \mathrm{s}$ \\
Purpose fulness & $29,60 \pm 0,89$ & $28,76 \pm 0,83$ & $\mathrm{n} / \mathrm{s}$ & $35,71 \pm 0,62$ & $36,71 \pm 0,56$ & $\mathrm{n} / \mathrm{s}$ \\
Perseverance & $19,00 \pm 0,77$ & $18,70 \pm 0,63$ & $\mathrm{n} / \mathrm{s}$ & $22,3 \pm 0,86$ & $22,61 \pm 0,60$ & $\mathrm{n} / \mathrm{s}$ \\
Fixing & $18,36 \pm 1,13$ & $20,85 \pm 0,70$ & $\mathrm{n} / \mathrm{s}$ & $20,91 \pm 0,66$ & $21,51 \pm 0,65$ & $\mathrm{n} / \mathrm{s}$ \\
Self-organization & $7,36 \pm 0,68$ & $9,58 \pm 0,73$ & $*$ & $7,4 \pm 0,51$ & $7,81 \pm 0,49$ & $\mathrm{n} / \mathrm{s}$ \\
Mood orientation & $7,60 \pm 0,40$ & $8,82 \pm 0,24$ & $*$ & $9,31 \pm 0,34$ & $9,21 \pm 0,34$ & $\mathrm{n} / \mathrm{s}$ \\
& Index & $16,52 \pm 0,46$ & $17,73 \pm 0,28$ & $*$ & $21,61 \pm 0,55$ & $22,1 \pm 0,45$ & $\mathrm{n} / \mathrm{s}$ \\
\hline
\end{tabular}

Note $*_{-} p \leq 0.05 ; * *_{-} p \leq 0.01 ; * * *_{-} p \leq 0,00 I ; n / s-$ insignificant 
In the group of Kuibyshev girls, there was a slight positive trend in most of the test indicators, however, there were no significant differences between the courses, and the level of absolute values was average. Such data may indicate that, during their studies, girls to a certain extent formed the ability to rationally organize their activities, achieve goals, overcome difficulties, and generally control their feelings, thoughts, and actions. However, the level of self-organization remained average, indicating a difficulty in implementing plans, possibly related to the social and environmental factors of a small city.

The "Life satisfaction" scale measures the cognitive assessment of the compliance of life capabilities with a person's expectations and reflects the overall measure of inner harmony and psychological satisfaction and probably has a close relationship with objective indicators of the success of a person's life. ${ }^{27}$

The data obtained (Table 2) indicate the average level of the "Life satisfaction" indicator in both groups. However, if in the Novosibirsk group this indicator remained at the same level as at the graduation rate, then in Kuibyshev it increased significantly by the end of training $(p \leq 0.01)$, remaining, however, only in the zone of average values.

These data may indicate that at the beginning of their studies, Novosibirsk students already had a fairly high level of life satisfaction, were ready to solve life tasks and master new forms of activity. However, by the end of their studies, they were either somewhat disappointed in their choice of profession, or significantly changed their opinion about their social status, revised the criteria for quality of life and more really approached the assessment of the prospects for professional and personal self-realization. This is partly due to the increased by the end of the study the realism of female students in assessing their own importance and the possibility of active influence on the world around them. However, from our point of view, a more weighty reason may be the specific socio-environmental and economic factors of a small city, where, despite the rather high level of training of graduates, the likelihood of employment and selfrealization seemed low. ${ }^{28}$

Viability characterizes the measure of a person's ability to withstand extreme and stressful situations, while maintaining the internal balance and efficiency of thinking that ensure the success of the activity as a whole. ${ }^{29}$ According to our data (Table 2), the values of the viability indicator in both groups were assessed as low. Despite the general upward trend in the indicator, by the end of the study, significant changes were observed only in Kuibyshev, which indicates the beneficial effect of the social and pedagogical conditions of the educational environment of the branch on the development of personal potential. The data from Novosibirsk girls indicate, perhaps, not so much about the high susceptibility of female students to stress (the results for the remaining scales were within the normal range), but about caution in assessing their own importance and value, unwillingness or inability to expand the limits of their capabilities.
Conscious planning of personal growth sets the focus on the search and the formation of a professional environment necessary for self-development and self-realization. Career "promotion" of a person in an adequate direction provides the possibility of achieving a high degree of respect and recognition, as well as high satisfaction with the quality of his own life. For students, due to age and psychophysiological characteristics, such circumstances become crucial, since, having formed, career orientations can remain stable in a person for a long time. ${ }^{30}$ The results of the test "Anchors of a career" indicate a statistically significant positive dynamics of indicators in the Novosibirsk group on the scales of "Service" and "Freedom for", and in the Kuibyshev group on "Entrepreneurship"; the level of all indicators in both groups was assessed as average. The girls of the district center, the positive dynamics of the "Entrepreneurship" indicator indicates an increased need to create something new, to have their own business and to achieve financial independence during the training (Table 3).

The growth of the indicators of the potential in the group of Novosibirsk testifies to a certain personal growth, striving working with people and the need for greater autonomy of action. Low indicators and the lack of significant dynamics in both groups on the "Challenge" scale may indicate not so much the unwillingness to compete, overcome obstacles and solve complex tasks, but rather the preference of planned and conscious activity to simple adventurism. ${ }^{31}$

Personal potential is an integral characteristic of the level of personal maturity, and its main phenomenon and form of manifestation is the level of self-determination of personality. ${ }^{32}$ To assess the level of self-determination of the surveyed contingent, we used the method "Scale of self-determination of personality". ${ }^{33}$ The data obtained on the "Authenticity" scale showed that the girls of Novosibirsk in the first year slightly advanced classmates from Kuibyshev (Table 4), but to graduation rate the values of this criterion are almost aligned.

The positive dynamics of the indicator was observed in the group of Kuibyshev girls $(p<0.05)$. On the scales of "Self-expression" and "Choice": significant and reliable progress was observed among female students of the metropolis and the graduation rate of these indicators were already higher among rural female students (Table 4). In general, the level of self-determination among female students, despite the different "intragroup" dynamics, was assessed as moderately low. The results indicate a certain dependence of girls on the opinions of others, their incomplete satisfaction with life, and their unwillingness to take responsibility for their own lives.

Test "Quality of life and satisfaction" 34,35 indicates that the physical activity and the activity of the study group "Emotional experiences" are more pronounced among female students in the district center, and the expansion of the "Sphere of communication" was more successful in the megalopolis students (Table 5).

Table 2 Comparison of performance scales "Life satisfaction", "Viability"

\begin{tabular}{|c|c|c|c|c|c|c|}
\hline \multirow[t]{2}{*}{ Indicator } & \multicolumn{3}{|c|}{ Novosibirsk } & \multicolumn{3}{|l|}{ Kuibyshev } \\
\hline & I course & 4 course & $p$ & I course & 4 course & $p$ \\
\hline Life satisfaction & $24,44 \pm 0,98$ & $24,30 \pm 0,88$ & $\mathrm{n} / \mathrm{s}$ & $20,9 \pm 0,86$ & $24.61 \pm 0.60$ & $* *$ \\
\hline Viability & $92.60 \pm 3.19$ & $94.91 \pm 2.51$ & $\mathrm{n} / \mathrm{s}$ & $110.5 \pm 4.2$ & $117.8 \pm 3.5$ & $* *$ \\
\hline
\end{tabular}

Note $*_{-}-p \leq 0.05 ; *_{-}-p \leq 0.01 ; * * *_{-} p \leq 0,001 ; n / s-$ insignificant 
Table 3 Comparison of the scale career orientations

\begin{tabular}{lllllll}
\hline Parameter & \multicolumn{7}{l}{ Novosibirsk } & \multicolumn{7}{c}{ Kuibyshev } \\
\cline { 2 - 7 } & I course & 4 course & $\boldsymbol{P}$ & I course & 4 course & $\boldsymbol{P}$ \\
\hline Serving & $4,85 \pm 0,16$ & $5,4 I \pm 0,15$ & $*$ & $5,40 \pm 0,10$ & $5,2 \pm 0,12$ & $\mathrm{n} / \mathrm{s}$ \\
Challenge & $3.70 \pm 0.27$ & $4.09 \pm 0.24$ & & $4.21 \pm 0.14$ & $4.22 \pm 0.13$ & $\mathrm{n} / \mathrm{s}$ \\
Business & $3.78 \pm 0.24$ & $4.23 \pm 0.15$ & & $3.61 \pm 0.18$ & $4.46 \pm 0.16$ & $*$ \\
Freedom "for" & $4.10 \pm 0.18$ & $4.79 \pm 0.17$ & $* *$ & $4.9 I \pm 0.12$ & $4.54 \pm 0.14$ & $\mathrm{n} / \mathrm{s}$ \\
Freedom "from" & $4,30 \pm 0,17$ & $4,82 \pm 0,14$ & & $4,80 \pm 0,11$ & $4,56 \pm 0,13$ & $\mathrm{n} / \mathrm{s}$ \\
\hline
\end{tabular}

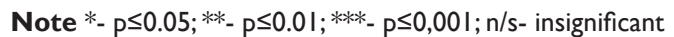

Table 4 Comparison of indicators on the scale "Self-determination of personality"

\begin{tabular}{|c|c|c|c|c|c|c|}
\hline \multirow[t]{2}{*}{ Scale } & \multicolumn{3}{|c|}{ Novosibirsk } & \multicolumn{3}{|l|}{ Kuibyshev } \\
\hline & I course & 4 course & $p$ & I course & 4 course & $p$ \\
\hline Authenticity & $15.04 \pm 0.53$ & $15.15 \pm 0.33$ & $n / s$ & $14.5 \pm 0.37$ & $|5.7| \pm 0.4 \mid$ & $*$ \\
\hline Self-expression & $8.80 \pm 0.27$ & $9.73 \pm 0.15$ & $* *$ & $10.3 \pm 0.25$ & $10.0 \pm 0.26$ & $\mathrm{n} / \mathrm{s}$ \\
\hline Selection & $13.16 \pm 0.76$ & $15.03 \pm 0.27$ & $*$ & $18.0 \pm 0.45$ & $18.5 \pm 0.47$ & $\mathrm{n} / \mathrm{s}$ \\
\hline Self-determination index & $|2.33 \pm 0.2|$ & $13.55 \pm 0.19$ & $* *$ & $14.30 \pm 0.25$ & $14.70 \pm 0.30$ & $\mathrm{n} / \mathrm{s}$ \\
\hline
\end{tabular}

Note ${ }^{*}$ - $\mathrm{p} \leq 0.05 ; * *_{-} \mathrm{p} \leq 0.01 ; * * *_{-} \mathrm{p} \leq 0,001 ; \mathrm{n} / \mathrm{s}$ - insignificant

Table 5 Comparison of indicators on a scale "Quality of life and satisfaction"

\begin{tabular}{|c|c|c|c|c|c|c|}
\hline \multirow[t]{2}{*}{ Indicator } & \multicolumn{3}{|l|}{ Novosibirsk } & \multicolumn{3}{|l|}{ Kuibyshev } \\
\hline & I course & 4 course & $\mathbf{p}$ & I course & 4 course & $\mathbf{p}$ \\
\hline Physical health & $15.12 \pm 0.34$ & $16.39 \pm 0.25$ & $* *$ & $|2.5| \pm 0.37$ & $|4.7| \pm 0.34$ & $* *$ \\
\hline Experiences & $21,12 \pm 0.42$ & $20.30 \pm 0.40$ & $\mathrm{n} / \mathrm{a}$ & $19.91 \pm 0.40$ & $21.31 \pm 0.30$ & $*$ \\
\hline Activity in free time & $10.52 \pm 0.36$ & $12.12 \pm 0.20$ & $* *$ & $10.10 \pm 0.28$ & $10.60 \pm 0.25$ & $* *$ \\
\hline Communication sphere & $20.08 \pm 0.49$ & $21.70 \pm 0.26$ & $* *$ & $20.61 \pm 0.38$ & $21.4 \pm 0.33$ & $\mathrm{n} / \mathrm{s}$ \\
\hline UCF index & $16.95 \pm 0.28$ & $17.63 \pm 0.17$ & $*$ & $16.10 \pm 0.28$ & $17.3 \pm 0.23$ & $* *$ \\
\hline
\end{tabular}

Note $*_{-}-\leq_{0.05} *_{-} *_{-} \leq 0.01 ; *_{*} *_{-}-0,00 I ; n / s-$ insignificant

Perhaps these results are due to the peculiarities of the subjective psycho-emotional perception of the social and living environment and the high level of self-assessment of the subjects. The ratio of these characteristics, obviously, has a positive effect on adaptation to new conditions and, as a result, allows us to devote more time to the development of new space, hobbies, social life, and sports. This assumption is confirmed by the dynamics of the Index of Satisfaction with Quality of Life, which statistically significantly increased in both groups.

\section{Conclusion}

The results indicate that there are significant differences in the dynamics of indicators of the personal potential of female students of the NSPU for the period of study, depending on the characteristics of the socio-pedagogical environment of universities in the metropolis and regional center. The specificity of such differences is associated with a change in the psychosocial status of students during the period of study at the university due to the influence of both positive and negative social and environmental, economic and cultural factors. These results may be important for the optimal construction and practical implementation of the educational process in the student's environment, depending on the course of study and the conditions of the educational environment.

\section{Acknowledgments}

None.

\section{Conflicts of interest}

The authors declare there is no conflict of interest.

\section{References}

1. Liman IA. Problems of financing higher education in the Russian Federation. University management: practice and analysis. 2005;5:3139.

2. Podolskaya EA. The contradictory social status of a modern student: a sociological dimension. Values and meanings. 2010;3(6):79-91.

3. Bocharskaya IA. Professional and socio-psychological adaptation of students in a higher education institution as a process of educating a socially oriented and competitive personality. Bulletin of Kazan State University of Culture and Arts. 2006;3:125-127. 
4. Bogomaz SA, Matsuta VV. Assessment of personal potential and identification of the main types of orientation to the professional activities of students. Psychology of education. 2010;12:77-88.

5. Leontiev DA. Personal potential: structure and diagnosis. 2011.

6. Krapohl E, Rimfeld K, Shakeshaft NG, et al. The high heritability of educational achievement reflects many genetically influenced traits, not just intelligence. Proc Natl Acad Sci U S A. 2014;111(42):15273-15278.

7. Rajchert JM, Żułtak T, Smulczyk M. Predicting reading literacy and its improvement in the Polish national extension of the PISA study: The role of intelligence, trait- and state-anxiety, socio-economic status and school-type. Learning and Individual Differences. 2014;33:1-11.

8. Klochko VE, Krasnoryadtseva OM. Peculiarities of "innovative potential of personality operational definition. Tomsk State University Journal. 2010;339:151-154.

9. Geryanskaya NO. Psychological teacher health in modernity educational conditions. Siberian Psychological Journal. 2008;29:6-89.

10. Negasheva MA, Manukyan AS. A multi-method approach to investigation of morphophysiological and psychological adaptation in young men and women-students of Moscow universities. Bulletin of Moscow University. 2016;2:49-58.

11. Kotovsky VV, Krasnoshchechenko IP. Representation of student youth about professional success. Bulletin of ChSPU. 2014;6:58-68.

12. Kienko EV, Morozova IS. The characteristis of levels of self-control of the person. Vestnik Kemsu. 2010;3:69-78.

13. Ananyev BG. On the problem of modern human knowledge. M Science. 1977:380.

14. Burns R. The development of self-concept and education. M Progress 1986:422

15. Borisov Yu A, Kudryavtsev IA. Semantic sphere of consciousness and self-consciousness of successful and unsuccessful middle managers. Psychological journal. 2003;24(1):91-103.

16. Gulyanova NA. On the connection of self-acceptance and awareness of the I-image in a situation of non-success. Vestnik Mosk. un-that. Psychology. 2001;3:68-75.

17. James U. Psychology. Pedagogy; 1991:368.

18. Zimbardo F. Formation of self-esteem: Self-consciousness and protective mechanisms of personality. Samara: House Bakhrakh; 2003:58.

19. Korneeva LN. Self-assessment as a mechanism for self-regulation of professional activity. Bulletin of LG. 1989;4:91-96.

20. Shibutani T. I-concept and self-esteem. Self-awareness and protective mechanisms of personality. Samara: House Bakhrakh; 2003:656.

21. Bogomaz SA, Matsuta VV. Estimation of personal potential and identification of the main types of orientation to professional activities of modern university students. Psychology of education . 2010;12:77-88.
22. Litvinova NA. The role of individual psycho-physiological features of students in adaptation to mental and physical activity: dis. Biol of Sciences. 2008:284.

23. Galai IA, Aizman RI. Pedagogical universities first-year students: gender peculiarities of the personal potential. Bulletin of the Novosibirsk State Pedagogical University. 2017;7(1):95-105.

24. Galai IA, Aizman RI, Bogomaz SA. Gender features of subjective evaluation of the basic values and possibilities of their implementing among the first year students of a pedagogical university. Siberian Psychological Journal. 2015;56:167-176.

25. Aizman RI, Lebedev AV, Aizman NI. Assessment of socio-psychological adaptation and personal potential of students. Certificate of state registration of computer program No. 2013615200. Moscow: FSUE Scientific and Technical Center; 2013.

26. Lytvina SA, Bogomaz SA, Galay IA, et al. Features of personalconditioned perception of university youth among the environment of the city (based on research in Irkutsk, Tomsk and Kuibyshev). Psychology in Economics and Management. 2014;1(11):106-111.

27. Osin EN, Leontiev DA. Testing the Russian-language versions of the two scales for rapid assessment of subjective well-being. Proceedings of the III All-Russian Sociological Congress. - Moscow: Institute of Sociology, Russian Academy of Sciences, Russian Society of Sociologists. 2008.

28. Galai IA, Lebedev AV, Aizman RI. Features of personal potential of students of high school in a megacity and the regional center. Bulletin of the Novosibirsk State Pedagogical University. 2015;3(25):94-101.

29. Bogomaz SA, Balanev D Yu. Hardiness as a component of individual innovation potential. Siberian Psychological Journal. 2009;32:23-28.

30. Bogomaz S.A. Modification of the questionnaire "Anchors of a career": a value orientation on innovative and entrepreneurial activity. Siberian Psychological Journal. 2012;44:101-109.

31. Petukhova Yu O. Value orientation on the challenge and risk acceptance as a component of the innovative potential of the individual. Diagnostics and the formation of motivational readiness for innovation in the context of continuous professional education: Materials of the All-Russian Scientific Conference. TML-Press. 2010;160:125-132.

32. Martynova MA, Bogomaz SA. Self-determination in the structure of the personal potential of modern Russian youth. TSU Bulletin. 2012;357:164-168.

33. Osin E, Oniwell I. Self-determination and well-being. Ghent, Belgium: Poster presented at the Self-Determination Conference; 2010.

34. Ritsner M, Kurs R, Gibel A, et al. Validity of an abbreviated Quality of Life Enjoyment and Satisfaction Questionnaire (Q-LES-Q-18) for schizophrenia, schizoaffective, and mood disorder patients. Qual Life Res. 2005;14(7):1693-1703.

35. Rasskazova EI. Evaluation of Quality of Life Enjoyment and Satisfaction: Psychometric Properties of a Russian-language Measure. Psychology-Journal of Higher School of Economics. 2012;9(4):81-90. 